\title{
Microbiota de mucosa vaginal e prepucial de felinos domésticos, clinicamente sadios, da região de Cuiabá - MT
}

\author{
Vaginal and prepucial microbiota of clinically healthy \\ feline from Cuiabá - MT - Brazil
}

\author{
Cássio Ricardo Ribeiro, ${ }^{*}$ Paula Diniz Galera, ${ }^{*}$ Marilda Oliveira Avila, ${ }^{\star *}$ Camila Barros Pantarotto, ${ }^{*}$ \\ Cristine Luciana de Carvalho**
}

\begin{abstract}
Resumo
Coletaram-se amostras da mucosa vaginal $(n=20)$ e prepucial $(n=20)$ de 40 felinos domésticos (Felis catus), clinicamente sadios, de ambos os sexos e diferentes faixas etárias, as quais foram submetidas à análise microbiológica. Os resultados obtidos da mucosa vaginal evidenciaram crescimento bacteriano em 18 das 20 amostras coletadas (80\%), sendo isoladas Escherichia coli (35\%), Staphylococcus spp (35\%, destes, $20 \%$ de Staphylococcus epidermidis, $10 \%$ Staphylococcus saprophyticus e $5 \%$ Staphylococcus aureus), Proteus sp. (20\%, destes, $10 \%$ Proteus mirabilis e $10 \%$ Proteus vulgaris) e Klebsiella sp (10\%). Dez das 20 amostras $(50 \%)$ da mucosa prepucial evidenciaram crescimento bacteriano, e observou-se Staphylococcus spp (20\%, destes, $15 \%$ S. epidermidis, $5 \%$ S. saprophyticus), Proteus mirabilis $(25 \%)$, Streptococcus faecalis $(5 \%)$ Yersinia sp (5\%). Não houve crescimento fúngico e de bactérias anaeróbias no material coletado. Os resultados encontrados neste estudo corroboram com os evidenciados na literatura existente.
\end{abstract}

Palavras-chave: felino, microbiota, vagina, prepúcio.

\begin{abstract}
A total of 40 samples from vaginal $(n=20)$ and prepucial $(n=20)$ mucosa of healthy cats were studied. From vaginal mucosa bacterial growth was obtained from $18(80 \%)$ samples, and were observed Escherichia coli (35\%), Staphylococcus spp (35\%), Proteus sp. (20\%) e Klebsiella sp (10\%). Bacterial growth was obtained from ten of the 20 prepucial samples and Staphylococcus spp $(20 \%)$, Proteus mirabilis (25\%), Streptococcus faecalis $(5 \%)$ Yersinia sp (5\%) were observed. Fungic growth was not obtained from the analysed material. The results observed in this study were similar to the literature.
\end{abstract}

Keywords: feline, microbiota, vagina, prepuce.

\section{Introdução}

Para se caracterizar uma infecção bacteriana deve-se inicialmente estabelecer quais os padrões de normalidade de uma espécie, isto é, sua flora normal. As infecções bacterianas do sistema urogenital estão entre as mais freqüentes infecções encontradas na prática de clínica de pequenos animais e geralmente são causadas por bactérias constituintes da flora normal do intestino e trato urogenital inferior (Barsanti, 1994). Entretanto, infecções bacterianas do trato urinário de felinos são menos comuns do que em caninos (Barsanti, 1998).

As infecções de vesícula urinária são causadas freqüentemente por bactérias indígenas, geralmente aeróbias, ascendentes da região prepucial, vagina ou área perianal (Lees, 1984). Pielonefrites decorrem, na maioria das vezes, de infecções ascendentes da vesícula urinária. A mucosa vaginal, prepucial e da uretra distal possuem uma microbiota ou flora bacteriana normal, fator de defesa contra organismos patogênicos. Esta microbiota deve ser considerada em resultados de culturas de urina, sêmen e descargas vaginais e prepuciais. A vesícula urinária é normalmente estéril, portanto, uma cultura positiva é indicativa de infecção ou contaminação durante a coleta da amostra (Barsanti, 1994).

Bactérias envolvidas em quadros de piometra em gatas derivam da microbiota vaginal que ascende do útero através da cérvix (Feldman e Nelson, 1996a). Em contraste com os caninos, infecções bacterianas são causa incomum de hematúria e disúria em felinos, ocorrendo em menos de $5 \%$ nos animais que apresentam tais sintomas (Barsanti, 1994; Osborne et al., 1995).

Como nas cadelas, gatas normais ou sadias geralmente apresentam bactérias dentro de seu trato vaginal, sendo em sua maioria aeróbias e representadas entre outras por Staphylococcus coagulase negativa (33 a 70\%), Streptococcus

\footnotetext{
* Departamento de Medicina Veterinária - Campus II - UPIS - Brasília, DF. SEPS 712/912 Conj. A - Asa Sul - Brasília , DF - CEP $70390-125$.

E-mail: pgalera@terra.com.br

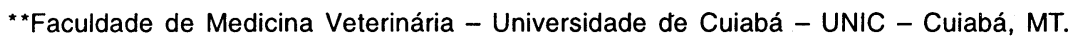


canis (20 a 80\%), Escherichia coli (20 a 66\%), Corynebacterium sp. $(23$ a $38 \%$ ) e bactérias anaeróbias (Feldman e Nelson, 1996a). Hirsch e Wiger (1977), Olson e Mather (1978), Ling e Ruby (1978), Doig et al. (1981) e Barsanti (1998) isolaram, em vagina de cadelas clinicamente sadias, Staphylococcus intermedius, Staphylococcus epidermidis, Streptococcus canis, Streptococcus viridans, Streptococcus zooepidemicus, Escherichia coli, Enterobacter spp., Pasteurella spp., Klebsiella spp., Proteus spp., Moraxella spp., Micrococcus spp., Neisseria spp., Flavobacterium spp., Corynebacterium spp., Pseudomonas spp., Mycoplasma spp., Ureaplasma spp.

Segundo Johnson (1992) e Grooters (1994), os resultados da cultura vaginal devem ser interpretados cautelosamente. A flora bacteriana normal da vagina canina, que é encontrada em $60 \%$ das amostras coletadas no vestíbulo vaginal cranial, é composta de estafilococos, estreptococos (alfa e betahemolíticos e não-hemolíticos), Escherichia coli, Pasteurella spp., Proteus spp., Haemophilus spp., entre outras. Não existem diferenças qualitativas nos tipos de bactérias isoladas das cadelas normais pré-púberes, ovariectomizadas ou maduras intactas, tampouco nas porções anterior e posterior da vagina, ou entre os vários estágios do ciclo estral. 0 Mycoplasma sp. e o Ureaplasma sp. também são habitantes normais da vagina canina. Eles foram observados em $88 \% \mathrm{e}$ $50 \%$, respectivamente, das culturas vaginais de 75 cadelas (Doig et al., 1981).

Poucos estudos foram realizados sobre microbiota vaginal de felinos. Jardim et al. (1992) estudaram a microbiota vaginal de 12 gatas adultas sadias, observando variações ao longo do ciclo estral e isolaram em suas amostras, como microrganismos mais prevalentes, Staphylococcus sp., Streptococcus sp. (beta e gama-hemolíticos) e enterobactérias, e ainda, lactobacilos, Corynebacterium $s p$. e Bacillus $s p$.

O estado geral de saúde do hospedeiro, contato prévio com determinados microrganismos, histórico médico, e uma variedade de agressões tóxicas, traumáticas, ou iatrogênicas são determinantes importantes da doença infecciosa. Frente à diminuição da resistência do hospedeiro, a microbiota indígena pode estar envolvida no desencadeamento da enfermidade infecciosa (Isenberg e D'amato, 1995). Desta forma, microrganismos endógenos, geralmente considerados de pouca virulência, não podem ser desprezados automaticamente como contaminantes em culturas bacterianas (Souza e Scarcelli, 2000).

Infecções do trato urinário geralmente são incriminadas a uma única espécie de bactérias, exceção feita a infecções secundárias complicadas por anormalidades funcionais ou anatômicas desta região. Destas infecções isolam-se com maior freqüência bactérias Gram-negativas como $E$. coli, Proteus spp., Klebsiella spp., Pseudomonas spp., Streptococcus spp., Enterococcus spp. Organismos Grampositivos (Staphylococcus spp., Streptococcus spp., Enterococcus spp.) ocorrem em aproximadamente 25\% das infecções do trato urinário. Infecções com Staphylococcus spp. e Proteus spp., que possuem urease, são fatores predisponentes para a formação de cálculos de estruvita (fosfatoamônia-magnésio hexaidratado) (Barsanti,1998).

Estudo realizado em felinos machos e fêmeas, com e sem obstrução uretral, evidenciou que menos de $3 \%$ dos animais apresentavam infecções bacterianas do trato urinário. Entre os uropatógenos isolados encontraram-se Escherichia coli, Staphylococcus spp., Streptococcus spp., Pasteurella spp., Proteus spp., Pseudomonas spp., Klebsiella spp. e Enterobacter spp (Osborne et al., 1995). A baixa freqüência com que bactérias têm sido isoladas da urina de felinos durante as fases iniciais da infecção do trato urinário resulta do comprometimento dos mecanismos de defesa locais do hospedeiro, mais efetivos nesta espécie (Osborne et al., 1995). Como ocorre em outras espécies, a micção normal (desimpedida, volume, freqüência e completa), a morfologia e funcionamento da uretra (que apresenta zona de alta pressão; contração e peristaltismo), e as propriedades antibacterianas intrínsecas da mucosa urinária (propriedades antibacterianas do epitélio celular; camada de glicosaminoglicanas, esfoliação celular, microbiota indígena) e da própria urina (hiperosmolalidade, altas concentrações de uréia, mucoproteína de Tamm-Horsfall e pH ácido) constituem defesas locais importantes do hospedeiro contra a colonização bacteriana do trato urinário dos felinos (Grauer, 1991; Barsanti, 1994).

Em outro estudo envolvendo 50 felinos, machos e fêmeas, com afecção do trato urinário inferior, evidenciou-se, em urocultura, obtida por cistocentese, crescimento bacteriano ( ${ }^{3}$ $100.000 \mathrm{UFC} / \mathrm{mL})$ em $8 \%(n=4)$ das amostras coletadas. Estas decorrentes de felinos com obstrução uretral recidivante. Isolaram-se Pasteurella sp., Klebsiella sp., Staphylococcus sp. e Escherichi coli (Reche Jr et al., 1998).

Não se evidenciaram estudos com microbiota prepucial de felinos na literatura compulsada. Há relatos destacando que, em cães machos, a flora bacteriana normal de uretra distal e de prepúcio pode levar à contaminação do sêmen utilizado para inseminação artificial. Nestes foram evidenciados Pasteurella multocida, Streptococcus beta-hemolítico, Escherichia coli, Mycoplasma spp e Staphylococcus coagulase negativa (Feldman e Nelson, 1996b).

\section{Material e métodos}

Utilizaram-se, neste experimento, 40 felinos domésticos (Felis catus), clinicamente sadios, de ambos os sexos e em várias faixas etárias, não castrados, sendo em sua maioria sem raça definida, criados com rações comerciais secas, encaminhados ao Hospital Veterinário da Universidade de Cuiabá (UNIC) para exames de rotina. Os animais não apresentavam alterações genitais ou sistêmicas. Coletaram-se 20 amostras de mucosa vaginal interna, e 20 de mucosa prepucial. A coleta foi realizada utilizando-se zaragatoas estéreis, através de friç̧ão na mucosa vaginal, evitando-se contato com a região externa da vulva, no caso das fêmeas; nos machos, a zaragatoa foi friccionada na mucosa prepucial, evitando-se contato com as estruturas adjacentes. As zaragatoas com os materiais coletados foram mantidas em caldo BHI (Infusão Cérebro Coração' ${ }^{1}$ e encaminhados para análise no Laboratório de Microbiologia do Hospital Veterinário da Universidade de Cuiabá (UNIC), onde foram incubados a $37^{\circ} \mathrm{C}$ durante 24 horas e semeados pela técnica de esgotamento de alça em placas contendo meios de ágar Blood base, ${ }^{2}$ suplementado com $10 \%$ de sangue de carneiro

\footnotetext{
1 Biobrás Diagnósticos - Montes Claros, MG - Brasil.

${ }^{2}$ Biobrás Diagnósticos - Montes Claros, MG - Brasil.
} 
desfibrinado e ágar MacConckey ${ }^{3}$ incubadas a $37^{\circ} \mathrm{C} \mathrm{em}$ aerobiose e anaerobiose, com utilização de jarra anaeróbica, durante 24 a 48 horas. A identificação bacteriana baseou-se nas características morfotintoriais e testes fenotípicos (Quinn et al.,1999).

Para a pesquisa de fungos, foi utilizado ágar Sabouraud dextrose $4 \%{ }^{4}$ acrescido de cloranfenicol, incubado à temperatura ambiente $\left(22^{\circ}\right.$ a $\left.25^{\circ} \mathrm{C}\right)$ durante 21 dias; e ágar Sabouraud dextrose $4 \%{ }^{4}$ acrescido de cloranfenicol e cicloheximida, incubado a $37^{\circ} \mathrm{C}$ durante 72 horas (Konemman et al., 1993).

\section{Resultados e discussão}

Os resultados obtidos da mucosa vaginal interna das fêmeas de felinos domésticos evidenciaram a presença de crescimento bacteriano em 18 das 20 amostras coletadas (80\%), observando-se crescimento de mais de uma cepa por amostra em apenas duas das fêmeas coletadas. As bactérias isoladas foram Escherichia coli (35\%), Staphylococcus spp (35\%, destes, $20 \%$ de Staphylococcus epidermidis, $10 \%$ Staphylococcus saprophyticus e 5\% Staphylococcus aureus), Proteus sp. (20\%, destes, $10 \%$ Proteus mirabilis e $10 \%$ Proteus vulgaris e Klebsiella sp (10\%).

Os resultados obtidos da mucosa prepucial dos machos de felinos domésticos evidenciaram a presença de crescimento bacteriano em dez das 20 amostras (50\%). Observou-se crescimento de mais de uma cepa por amostra em somente um macho coletado. Proteus mirabilis (25\%), Staphylococcus spp (20\%, destes, $15 \%$ S. epidermidis, $5 \%$ S. saprophyticus), Streptococcus faecalis (5\%) Yersinia sp (5\%) foram isolados.

Não houve crescimento fúngico nas 40 amostras analisadas. Esse fato talvez possa ser atribuído ao fato de que normalmente fungos saprófitas não são encontrados na mucosa vaginal e prepucial (Quinn et al., 1999).

Segundo Corrêa e Corrêa (1978), Konemman et al. (1993) e Quinn et al. (1999), bactérias do gênero Proteus mirabilis residem em animais saudáveis, e também podem ser agente causal de infecções do trato urinário e em feridas infectadas, mormente nos indivíduos imunossuprimidos. Staphylococcus saprophyticus, embora de baixa patogenicidade, podem ser causadores de infecção hospitalar, bem como ser integrante da microbiota normal associado a outras bactérias. As enterobactérias, importantes patógenos humanos e animais, são habitantes da flora intestinal de diversas espécies, responsáveis por enterite, infecção do trato respiratório inferior ou superior, meningite, infecção do trato urinário e infecção de feridas. Podem, ainda, estar presentes em amostras de diferentes sistemas em animais normais.

Quanto às bactérias anaeróbicas, geralmente não são encontradas em mucosas normais; porém, quando presentes, estão relacionadas com processos patológicos (Konemman et al., 1993; Quinn et al., 1999).

\section{Conclusões}

Frente aos resultados obtidos a partir da análise da microbiota da mucosa vaginal, podemos concluir que:

$>$ Houve crescimento bacteriano em $80 \%$ das amostras coletadas;

$>$ Observou-se crescimento bacteriano de somente uma cepa por amostra em $89 \%$ das culturas positivas;

$>$ Não houve crescimento fúngico e de bactérias anaeróbias nas amostras coletadas;

$>$ As bactérias isoladas foram Escherichia coli (35\%), Staphylococcus spp (35\%, destes, $20 \%$ de Staphylococcus epidermidis, 10\% Staphylococcus saprophyticus e $5 \%$ Staphylococcus aureus), Proteus sp. (20\%, destes, $10 \%$ Proteus mirabilis e 10\% Proteus vulgaris e Klebsiella $s p$ $(10 \%)$.

Quanto aos resultados obtidos a partir da análise da mucosa prepucial, podemos concluir que:

$>$ Houve crescimento bacteriano em $50 \%$ das amostras coletadas;

$>$ Observou-se crescimento bacteriano de somente uma cepa por amostra em $90 \%$ das culturas positivas;

$>$ Não houve crescimento fúngico e de bactérias anaeróbias nas amostras coletadas;

$>$ As bactérias isoladas foram Proteus mirabilis (25\%), Staphylococcus spp (20\%, destes, $15 \%$ S. epidermidis, $5 \%$ S. saprophyticus), Streptococcus faecalis (5\%) Yersinia sp (5\%).

Os resultados evidenciados neste estudo corroboram com os encontrados na escassa literatura existente. Entretanto, salienta-se a necessidade de estudos adicionais, nas diversas regiões do Brasil, que venham a contribuir para adoção com sucesso de condutas terapêuticas apropriadas na espécie felina.

Agradecimentos ao Hospital Veterinário da Universidade de Cuiabá - UNIC - MT.

\section{Referências}

BARSANTI, J.A., FINCO, D.R., BROWN, S.A. Diseases of the lower urinary tract. In: SHERDING, R.G. The cat: diseases and clinical management. 2. ed. Philadelphia:W.B.Saunders, 1994, p. 1.769-1.823.

BARSANTI, J.A. Genitourinary infections. In: GREENE, C.E. Infectious Diseases of the Dog and Cat. 2. ed. Philadelphia: W.B. Saunders, 1998 , p. 626-646.

\footnotetext{
${ }^{3}$ Biobrás Diagnósticos - Montes Claros, MG - Brasil
}

${ }^{4}$ Sanofi Diagnostics Pasteur - França
CORREA, W. M.; CORREA, C.N.M.. Enfermidades infecciosas dos mamíferos domésticos. 2. ed. São Paulo: J.M. Varella, 1978.

DOIG, P.A. The genital Mycoplasma and Ureaplasma flora of healthy and diseased dogs. Can. J. Comp. Med. v. 45, p. 233-237, 1981.

FELDMAN, E.C.; NELSON, R.W. Feline reproduction. In: Canine and feline endocrinology and reproduction. 2. ed. Philadelphia: W.B. Saunders, 1996a, p. 741-768.

FELDMAN, E.C.; NELSON, R.W. Clinical diagnostic evaluation of the male reproduction tract. In: Canine and feline endocrinology and reproduction. 2. ed. Philadelphia: W.B. Saunders. 1996b. p. 673690. 
GRAUER, G.F. Urinary tract infections. In: ALLEN, D.G. et al. Small animal medicine. Philadelphia: J.B.Lippincott, 1991, p. 625-633.

GROOTERS, A.M. Diseases of the vagina and vulva. In: BIRCHARD, S.J. \& SHERDING, R.G. Saunders Manual of Small Animal Practice. Philadelphia: W.B. Saunders, 1994, p. 912-917.

HIRSCH, D.C.; WIGER, N. The bacterial flora of the normal canine vagina compared with that of vaginal exudates. Journal Small Animal Practice, n. 18, p. 25-30, 1977.

ISENBERG, H.D.; D'AMATO, R. Indigenous and pathogenic microorganisms of humans. In: MURRAY, P.R.; BARON, E.J.; PFALLEN, M.A.; TENOER, F.C.; YOLKEN,R.H. Manual of clinical microbiology. Washington:ASM Press, 1995, p. 5-18.

JARDIM, P.C.S.; VICENTE, W.R.R.; SCHOCKEN-ITURRINO, R.P. Avaliação da microbiota vaginal, em fêmeas felinas adultas, durante as fases do ciclo estral. CONGRESSODEINICIAÇÃO CIENTÍFICADA UNESP, 4., 1992, Araçatuba. Resumos..., 1992. p.103-104.

JOHNSON, C.A. Patologias da vagina. In: ETTINGER, S.J. Tratado de Medicina Interna Veterinánia. 3. ed. São Paulo: Manole, 1992. p. 1.8861.893.
KONEMMAN, E.W.; ALLEN, S.D.; DOWELL, V.R.; SOMMERS, H.M.. Diagnóstico Microbiológico Texto e Atlas Colorido. 2. ed. São Paulo: Panamericana, 1993.

LEES, G.E. Epidemiology of naturally occuring feline bacterial urinary tract infections. Vet. Clin. North Am. Small Anim. Pract. v.14, p. 471475, 1984.

LING, G.V.; RUBY, A.L. Aerobic bacterial flora of the prepuce, urethra and vagina of normal adult dogs. Am. J. Vet. Res. n. 39, p. 695-698, 1978.

OLSON, P.N. \& MATHER, E.C. Canine vaginal and uterine bacterial flora. J. Am. Vet. Med. Assoc., v. 172, p.708-712, 1978.

OSBORNE, C.A., KRUGER, J.M., LULICH, J.P., POLZIN, D.J. Disorders of the feline lower urinary tract. In: OSBORNE, C.A., FINCO, D.R. Canine and feline nephrology and urology. Philadelphia: Lea \& Febiger, 1995, p. 625-680.

QUINN, P.J.; CARTER, M.E.; MARKEY, B.; CARTER, G.R.. Clinical Veterinary Microbiology. London: Mosby, 1999.

RECHE JR., A.; HAGIWARA, M.K.; MAMIZUKA. Estudo clínico da doença do trato urinário inferior em gatos domésticos de São Paulo. Braz. J. Vet. Res. Anim. Sci. v. 35, n. 2, p. 69-74, 1998.

SOUZA, C.A.I.; SCARCELLI, E.. Agressão por microorganismos da microbiota endógena. Arq. Inst. Biol. v. 67, n. 2, p. 275-281, 2000. 